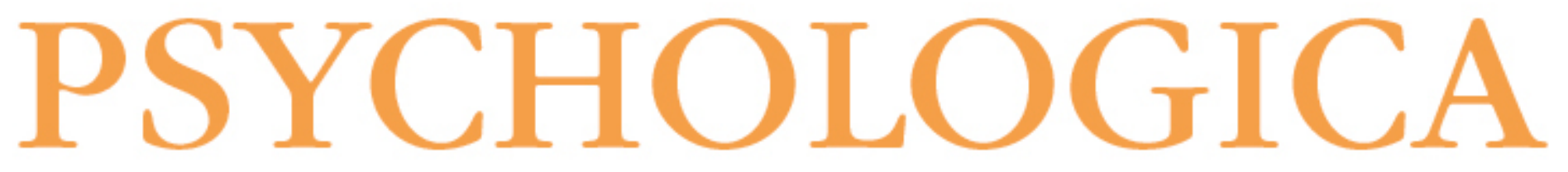

\title{
A formação inicial de terapeutas infantis: o caso do Serviço de Atendimento Clínico da Faculdade de Psicologia da Universidade de Lisboa
}

Autor(es): $\quad$ Sá, Isabel; Silva, Adelina Lopes da

Publicado por: Imprensa da Universidade de Coimbra

URL

persistente: URI:http://hdl.handle.net/10316.2/5474

DOI: DOI:http://dx.doi.org/10.14195/1647-8606_51_9

Accessed : $\quad$ 26-Apr-2023 01:49:36

A navegação consulta e descarregamento dos títulos inseridos nas Bibliotecas Digitais UC Digitalis, UC Pombalina e UC Impactum, pressupõem a aceitação plena e sem reservas dos Termos e Condições de Uso destas Bibliotecas Digitais, disponíveis em https://digitalis.uc.pt/pt-pt/termos.

Conforme exposto nos referidos Termos e Condições de Uso, o descarregamento de títulos de acesso restrito requer uma licença válida de autorização devendo o utilizador aceder ao(s) documento(s) a partir de um endereço de IP da instituição detentora da supramencionada licença.

Ao utilizador é apenas permitido o descarregamento para uso pessoal, pelo que o emprego do(s) título(s) descarregado(s) para outro fim, designadamente comercial, carece de autorização do respetivo autor ou editor da obra.

Na medida em que todas as obras da UC Digitalis se encontram protegidas pelo Código do Direito de Autor e Direitos Conexos e demais legislação aplicável, toda a cópia, parcial ou total, deste documento, nos casos em que é legalmente admitida, deverá conter ou fazer-se acompanhar por este aviso. 
NÚMERO 51

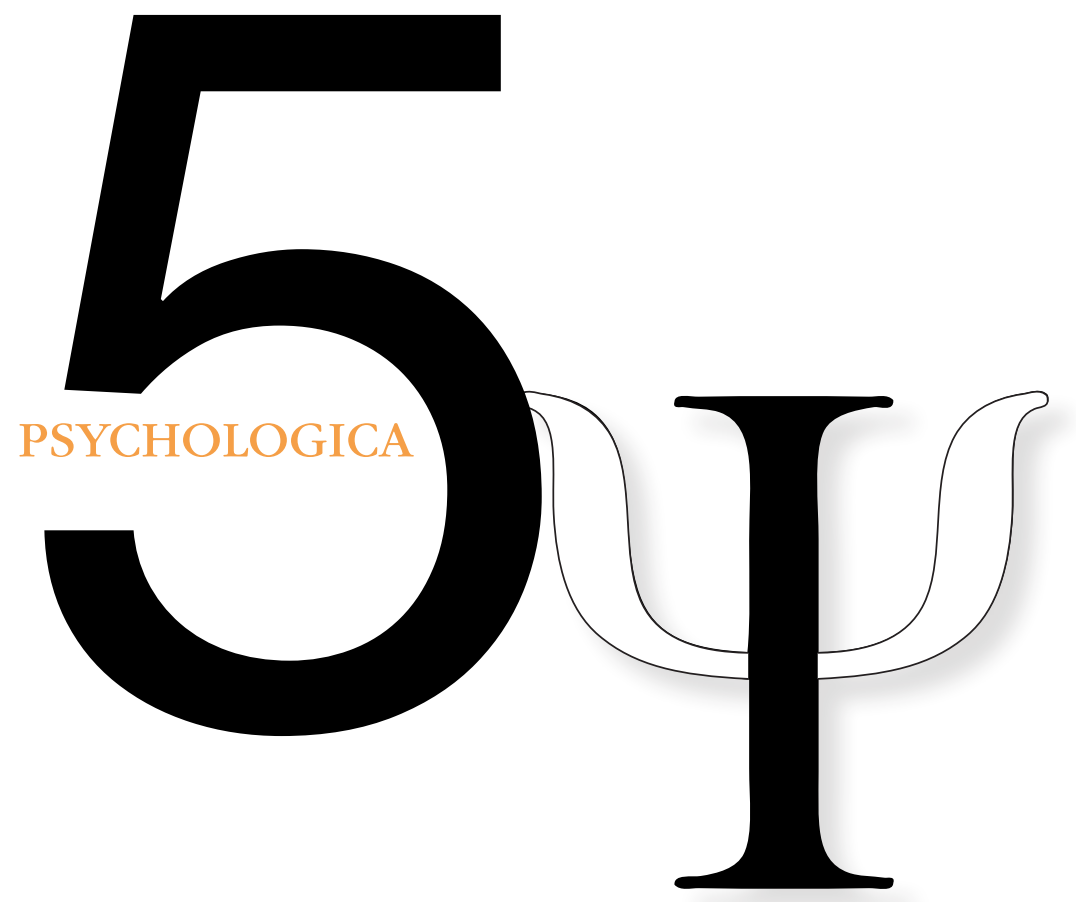

IMPRENSA DA UNIVERSIDADE DE COIMBRA

FACULDADE DE PSICOLOGIA E DE CIÊNCIAS DA EDUCAÇÃO DA UNIVERSIDADE DE COIMBRA 


\section{A formação inicial de terapeutas infantis: o caso do Serviço de Atendimento Clínico da Faculdade de Psicologia da Universidade de Lisboa}

Isabel Sá \& Adelina Lopes da Silva'

Os objectivos deste estudo são: (a) descrever a intervenção psicológica proporcionada pelo Serviço de Atendimento Clínico do Núcleo Cognitivo Comportamental Integrativo da FPCE-UL no que se refere às modalidades de intervenção e à supervisão clínica; e (b) caracterizar as crianças, jovens e pais que solicitam ajuda, em termos de sexo, idade, nível sócio-cultural, problemas apresentados e fonte de referência. Foi utilizada uma metodologia documental retrospectiva através da análise dos processos clínicos. Os dados revelam que nos últimos oito anos, foram atendidos no Serviço 93 crianças e adolescentes (61 rapazes e 32 raparigas), entre os 4 e os 18 anos de idade $(M=11,3)$, apresentando diversos problemas emocionais e de comportamento e os processos de intervenção têm a duração média de 12 sessões. Por fim, os resultados são discutidos e analisados retirando-se implicações para a adequação deste tipo de Serviço à formação clínica inicial de psicólogos.

PALAVRAS-CHAVE: terapia infantil; supervisão clínica; formação de psicólogos; atendimento psicológico.

\section{Introdução}

A formação em saúde mental infantil enfatiza a importância de uma abordagem relacional na avaliação, na intervenção e no tratamento dos problemas da infância. A "prática reflectida" tem, igualmente, um papel central e envolve a supervisão reflexiva como uma parte importante do treino e da aprendizagem de forma a facilitar a resolução de problemas e enquadrar de forma sensata as situações problemáticas (Osofsky, 2005).

Os psicólogos em formação precisam de adquirir um sólido enquadramento conceptual que lhes permita orientar os seus processos de avaliação, formulação de caso e intervenção (o "saber"), como também de aplicar esses conhecimentos em contextos reais que lhes permitam adquirir competências (o "saber fazer") e

\footnotetext{
1 Faculdade de Psicologia da Universidade de Lisboa isabel.sa@fp.ul.pt
} 
desenvolver atitudes e consciência deontológica (o "saber estar"). No contexto do treino dos psicólogos/terapeutas a "supervisão" constitui uma forma privilegiada de atingir estes objectivos.

O processo de supervisão refere-se às actividades planeadas realizadas por um profissional mais qualificado (o supervisor) cuja função é fazer uma análise crítica do trabalho realizado por uma pessoa menos qualificada (o terapeuta em formação), de forma a facilitar o desenvolvimento profissional e pessoal deste último, isto é, a sua competência para actuar eficazmente de forma independente (Perris, 1994). A grande responsabilidade do supervisor é ajudar o terapeuta noviço a tornar-se suficientemente competente para não comprometer o bem estar do paciente, bem como assegurar-se de que o nivel de competência do supervisando corresponde aos padrões deontológicos e científicos estabelecidos para a profissão.

Os Serviços Clínicos inseridos nas Faculdades de Psicologia permitem, não só, o treino dos estudantes, fornecendo uma oportunidade de aplicação dos conhecimentos teóricos adquiridos, mas também cumprem uma função social importante. Na primeira área, permitem a formação de profissionais adequadamente habilitados e capazes de expandir as suas práticas psicológicas de acordo com as novas exigências sociais e politicas. Na segunda, oferecem a uma população economicamente desfavorecida a possibilidade de acederem a serviços psicológicos gratuitos ou de baixo custo (Peres, Santos \& Coelho, 2004).

Tendo por objectivo oferecer os serviços mais eficazes à comunidade e formar os estudantes em termos éticos, técnicos e reflexivos, importa conhecer as características da população que recorre a estes serviços e o tipo de resposta que é dado.

A caracterização dos utentes e dos serviços prestados permite conhecer as necessidades específicas da população e melhor adequar a intervenção oferecida. Estudos deste tipo têm-se revelado imprescindiveis para o aperfeiçoamento das práticas clínicas já existentes e para a criação de novos serviços ou modalidades de atendimento.

Além disso, dada a inserção dos Serviços no contexto da formação Superior, devem também verificar se estes oferecem oportunidades para a adequada formação de profissionais (Enéas, Faleiros, \& Sá, 2000).

Desde a década de oitenta do século passado que a FPCE-UL tem Serviços à Comunidade em diferentes sectores. O presente artigo procura caracterizar o serviço clínico de atendimento a crianças e jovens do Núcleo de Psicoterapia Cognitivo-Comportamental Integrativa (NPCCI) de forma a assegurar a eficácia das intervenções e a sua adequabilidade à formação de psicólogos clínicos. 
Este serviço clínico dentro da Universidade de Lisboa oferece um atendimento gratuito à comunidade, sendo ao mesmo tempo um local onde os estudantes de Psicologia recebem treino e supervisão no atendimento de casos clínicos com o objectivo de os capacitar para a prática e a reflexão sobre o exercício profissional. 0 atendimento realiza-se na modalidade de terapia breve para crianças e adolescentes, de cariz cognitivo-comportamental, realizado por estudantes do $2^{\circ}$ ano do $2^{\circ}$ ciclo de estudos do Mestrado Integrado em Psicologia, sob supervisão de docentes.

Os objectivos deste estudo são: (a) descrever a intervenção psicológica proporcionada pelo Serviço de Psicologia no que se refere às modalidades de intervenção e à supervisão clínica; e (b) caracterizar as crianças, jovens e pais que solicitam ajuda, em termos de sexo, idade, nível sócio-cultural, problemas apresentados e fonte de referência.

\subsection{Funcionamento do Serviço}

No NPCCl os utentes inscrevem-se directamente ou através do telefone, ficando em lista de espera até ser feito o atendimento que, geralmente, decorre entre Outubro e Março de cada ano lectivo. Dado o número limitado de recursos humanos do Serviço não é feita nenhuma divulgação formal do mesmo. Apesar disso, existe sempre uma lista de espera e o espaço de tempo até se ser atendido pode ir dos 6 meses a 1 ano.

Na primeira sessão, frequentemente com a presença de um supervisor, é feito o atendimento aos pais ou outros encarregados de educação, onde se procura identificar a queixa, obter uma história do desenvolvimento da criança e/ou do problema, e a presentar, verbalmente e por escrito, a forma de funcionamento dos Serviços. Após esta primeira informação é decidido como vai ser feita a avaliação do(s) problema(s) (quem, quando, como e onde vai ser avaliado) ou se é mais indicado encaminhar o caso para outro Serviço dentro ou fora da Faculdade (Terapia Familiar, Orientação Escolar, Psicólogo da Escola, Serviço de Saúde Mental, etc.). Dado o atendimento ser realizado maioritariamente por estudantes e se tratar de intervenções breves algumas perturbações não são acompanhadas (por ex.: perturbações do desenvolvimento, do comportamento alimentar, toxicodependências, dificuldades específicas na aprendizagem).

Caso o acompanhamento prossiga no Serviço, segue-se um processo de avaliação mais amplo, com a duração aproximada de 4-5 sessões, para a definição do problema, após o qual são devolvidos os resultados aos encarregados de educação e aos próprios jovens. Ao mesmo tempo é apresentado um plano com objectivos e estratégias de intervenção que dará lugar a um acompanhamento em sessões 
semanais de 50 minutos, caso os intervenientes concordem em dar continuidade ao processo.

Os acompanhamentos terminam quando são atingidos os objectivos ou os resultados obtidos são satisfatórios para os intervenientes no processo.

\subsection{Supervisão Clínica}

Durante o seu estágio no Serviço, os estudantes têm reuniões semanais de supervisão clínica, em pequenos grupos (4 a 5 estudantes) onde são discutidos e analisados os casos em acompanhamento, as sessões de avaliação ou intervenção realizadas e planeadas as próximas sessões. Este treino prático permite aos estudantes: (a) aprender a utilizar eficazmente diferentes instrumentos de avaliação e a organizar a informação obtida através da conceptualização de caso; (b) aprender e praticar uma gama de intervenções cognitivo-comportamentais sob supervisão constante; (c) adquirir os conhecimentos e as competências necessárias à manutenção de uma boa relação terapêutica com as crianças, adolescentes e pais; (d) conhecer e aprender a resolver problemas éticos que surgem com frequência na prática clínica, e (f) desenvolver as competências de reflexão pessoal que promovem uma "prática reflexiva".

De forma geral, a supervisão consiste uma hierarquia de tarefas durante um largo período de tempo e o supervisor é visto como uma pessoa que combina e utiliza as qualidades de docente e terapeuta de acordo com as situações específicas (Perris, 1994).

Enquanto docente, o supervisor identifica lacunas no conhecimento dos estudantes e assume um papel didáctico colmatando essas lacunas e introduzindo novos conhecimentos necessários aos casos específicos em acompanhamento, servindo de modelo, dando apoio e instruções.

Enquanto terapeuta, o supervisor pode transferir para o contexto da supervisão o princípio do "empirismo colaborativo", defendido por Beck (1976) como um dos mais importantes fundamentos da aliança terapêutica na terapia cognitiva, o que constitui uma base sólida para construir uma relação caracterizada pela confiança, respeito e compreensão mútuas. Em particular, a aplicação coerente do princípio da colaboração e o uso consistente do diálogo socrático, contribuem para limitar a experiência de dependência do supervisando, uma vez que promovem a sua participação activa na procura de comportamentos terapêuticos mais adequados. Segundo Yogev (1982) que, tal como outros autores (Bernard \& Goodyear, 1992), sugere uma sequência desenvolvimentista para a formação inicial dos terapeutas, o modelo 
de supervisão deve integrar três orientações: "compreender os problemas do cliente; adquirir as competências e técnicas que podem ajudar no trabalho com os clientes; e tomar consciência de que independentemente da qualidade do terapeuta na avaliação, diagnóstico, compreensão teórica e uso de técnicas eficazes para lidar com os problemas do cliente, também têm de procurar compreender-se a si mesmos e usar os seus sentimentos e comportamentos como instrumentos terapêuticos" (pp. 236-237).

A nossa própria experiência enquanto supervisoras leva-nos a partilhar o modelo de Yogev (1982) que vê o desenvolvimento dos estudantes desenrolar-se em três estádios: a definição do papel, a aquisição de competências e a consolidação e avaliação da prática.

Para o terapeuta em formação, ter de confrontar-se com o seu primeiro paciente sob supervisão implica um importante "ritual de passagem" da fase da aprendizagem teórica dos princípios básicos da psicoterapia para a fase da "acção" na prática. Assim o primeiro estádio envolve a definição de novos papéis nas suas vidas: ser terapeuta e supervisando em avaliação.

Esta é uma fase que os estudantes enfrentam com grande ansiedade duvidando das suas capacidades para serem terapeutas eficazes e apresentam, muitas vezes, expectativas irrealistas. Por exemplo, "acreditar que um bom terapeuta tem todas as respostas, vê para além da superfície e sabe exactamente o que fazer em qualquer situação terapêutica" (Yogev, 1982, p.238).

Neste primeiro estádio é fundamental ajudar a compreender o que significa ser terapeuta, desmistificando percepções do papel do terapeuta e clarificando expectativas, expressar a ansiedade e as expectativas catastróficas (por exemplo, o cliente não vai voltar, não me vai levar a sério, posso fazer algo durante a sessão com consequências negativas), compreender as próprias limitações e sentimentos de inadequação face ao papel de terapeuta e compreender os seus aspectos positivos e que possuem conhecimentos de base.

A supervisão em grupo ajuda a atingir estes objectivos na medida em que podem reconhecer que todos partilham os mesmos sentimentos e têm preocupações semelhantes.

Um outro aspecto crucial nesta fase para o supervisor é o de procurar um equilíbrio entre a dependência completa e a autonomia do estudante. Um dos problemas do supervisando neste período é a compreensível falta de confiança na sua habilidade relacionada com o dilema inerente ao próprio conceito de supervisão: a aceitação implícita pelo supervisando de um estado de incompetência embora limitado a uma área específica. Esta característica faz com que muitos supervisandos se tornem totalmente dependentes do supervisor, esperando um feedback específico das 
sessões anteriores e indicações precisas sobre o que fazer nas sessões seguintes. No entanto, embora algum grau de dependência seja de esperar nesta fase inicial, o estudante tem de perceber que o que está em causa é o desenvolvimento da sua própria perícia e identidade profissional.

136 Ao contrário, alguns supervisandos abordam esta sua primeira experiência com uma confiança excessiva nas suas competências e têm relutância em discutir aspectos de cariz mais interpessoal que podem estar a interferir na sua aprendizagem, recusando discutir aspectos de índole mais pessoal. Dada a abordagem cognitiva à psicoterapia, torna-se particularmente relevante a identificação e correcção dos "esquemas interpessoais" disfuncionais que o paciente pode ter desenvolvido e o seu possivel impacto na relação terapeuta-paciente, aspectos salientes para a discussão nas sessões de supervisão (Safran \& Muran, 2001).

Deste modo, uma das principais tarefas do supervisor nesta fase inicial é a de discutir abertamente os limites da intervenção do supervisor (por exemplo, não é um terapeuta do estudante), as expectativas do supervisor e os objectivos da relação de supervisão.

Um outro factor a acrescentar à ansiedade inicial dos estudantes é o facto de um dos papéis do supervisor ser o de fazer uma avaliação formal que conduzirá à atribuição de um diploma por parte da instituição. Para a maioria dos supervisandos, obter uma má classificação no estágio tem mais impacto do que receber uma má classificação numa disciplina. A avaliação que o supervisor faz da competência do estudante enquanto psicoterapeuta põe em causa a sua auto-imagem quer enquanto pessoa, quer relativamente às suas expectativas profissionais nesta área.

É importante que o supervisor clarifique desde o início como e quando vai ser feita a avaliação e com que bases, de forma a que a supervisão seja um espaço aberto ao dialogo e em que o estudante se sinta à vontade para colocar as suas dúvidas e aprender com os seus erros em vez de evitar partilhar as suas dificuldades com medo de ser avaliado negativamente.

Uma fonte comum de confusão para o formando é a sua inabilidade para distinguir entre uma avaliação feita pelo supervisor referente às suas competências enquanto terapeuta e o progresso do paciente durante a terapia. Nestes casos, é essencial que o supervisor ajude o formando a distinguir entre aspectos relacionados com a sua competência e identidade profissional e aqueles que se referem a questões completamente para além do seu controlo (Perris, 1994).

Assim, deve o supervisor clarificar desde o início quais as expectativas face ao desempenho dos estudantes ao longo do ano (progressiva autonomia do supervisando na auto-avaliação e apresentação de sugestões) e o que vai ser avaliado (a atitude e comportamento do supervisando durante as sessões clínicas e de 
supervisão; a capacidade de exposição e auto-reflexão) que não deve nunca ser colocado em termos dos resultados obtidos com os pacientes.

Depois de existir uma compreensão clara daquilo que se espera dos estudantes e de ter sido dissipada a ansiedade inicial é possível passar ao estádio seguinte de aquisição de competências.

(sobre os assuntos a abordar na primeira entrevista, bem como outros aspectos pertinentes: expectativas sobre a terapia, estabelecer a relação e observar o paciente e a sua reacção a este), na forma de simulações através do role playing em grupo desta primeira entrevista e através da observação do supervisor durante uma primeira entrevista.

Esta fase de observação é fundamental para diminuir a ansiedade do supervisando desmistificando o que se passa durante uma sessão e ajudando-o a sentir-se mais competente.

A terceira fase é a consequência natural das anteriores e consiste nos supervisandos receberem os seus próprios pacientes e apresentarem as suas primeiras entrevistas durante a supervisão. Agora a relação de supervisão inclui tanto o aspecto emocional-experiencial do primeiro estádio, como o aspecto mais didáctico e de prática de competências do segundo estádio (Yogev, 1982).

Neste estádio, aquilo que acontece vai ser em grande parte determinado pelas necessidades dos casos em acompanhamento e das características e necessidades de cada estudante, e o supervisor orienta as sessões para uma maior reflexão pessoal e auto-avaliação das aquisições que os próprios estudantes vão fazendo.

De forma geral as sessões de supervisão decorrem em pequenos grupos mas, de acordo com as necessidades, podem realizar-se supervisões individuais, solicitadas pelo próprio estudante ou por iniciativa do supervisor, quando estão em causa aspectos mais pessoais ou necessidades específicas dos formandos.

\section{Método}

Neste estudo foi utilizada uma metodologia documental retrospectiva, através da análise de todos os relatórios de caso atendidos no Serviço e efectuados pelos estudantes. 
São apresentados os dados referentes aos últimos 8 anos (1998-2006). Durante este período foram atendidas 93 crianças e adolescentes (61 rapazes e 32 raparigas), com idades compreendidas entre os 4 e os 18 (Média $=11,33$ anos) (cf. Figura 1). Em relação ao nível socio-cultural, $25,8 \%$ das famílias apresentam um nível baixo, $28,0 \%$ um nível médio e $25,0 \%$ um nível alto.

O Quadro 1 apresenta a distribuição da amostra pelos anos de escolaridade, verificando-se que a maior procura de ajuda nos $1^{\circ}, 7^{\circ}$ e $9^{\circ}$ anos de escolaridade, bem como no $1^{\circ}$ e no $3^{\circ}$ Ciclo do Ensino Básico.

O Quadro 2 apresenta o tipo de queixas/problemas que levam os pais e/ou encarregados de educação a procurar ajuda para os seus filhos. Como se pode verificar estas são muito diversificadas, mas as mais frequentes são sem dúvida o insucesso escolar e os problemas de comportamento.

No Quadro 3 são apresentadas as fontes de referência dos casos, podendo verificar-se que quem mais indica o Serviço são os docentes da própria Faculdade, os professores e os psicólogos das escolas que as crianças e jovens frequentam.

Os problemas identificados após o processo de avaliação são apresentados no Quadro 4. Os mais frequentes são um desempenho escolar inferior às capacidades da criança, competências interpessoais deficientes ou inadequadas e ansiedade.

O processo de intervenção dura entre 1 e 29 sessões, sendo o número médio de sessões de 12. Alguns casos não necessitam de intervenção, outros são encaminhados para outros serviços (2,1\%). $43 \%$ dos processos de intervenção situa-se entre 1 e 10 sessões, $39,8 \%$ entre as 11 e 20 sessões, e apenas $15,1 \%$ dura mais de 20 sessões.

As principais estratégias de intervenção utilizadas são apresentadas no Quadro 5.

\section{Discussão e implicações dos resultados}

Os resultados indicam que, embora apenas um pequeno número de casos seja atendido em cada ano lectivo, as dificuldades comportamentais e emocionais apresentadas pelas crianças e as suas famílias fornecem uma vasta experiência em técnicas de avaliação e estratégias de intervenção.

Globalmente, os dados obtidos permitem caracterizar o perfil dos utentes que mais recorrem ao serviço: são de nacionalidade portuguesa (78\%), do género masculino (66,3\%), com uma idade média de 11 anos, frequentando o $2^{\circ}$ ciclo do ensino básico, referenciado por um professor ou um psicólogo escolar (21,6\%), com um problema de insucesso escolar ou de relacionamento interpessoal (30,1\%), e que foi acompanhado em média durante 12 sessões. 
Tal como foi verificado noutros estudos (Romaro \& Capitão, 2003), durante a infância e a adolescência, verifica-se uma predominância dos pacientes do género masculino, tendência que se inverte a partir dos 15 anos. No nosso estudo, a única excepção encontra-se aos 7 anos em que surge uma percentagem maior de raparigas.

Relativamente às queixas apresentadas, muitos dos casos manifestam mais do que uma queixa, sendo a maioria de cariz externalizante (agressividade, desobediência, problemas de comportamento) ou de insucesso escolar.

Comparativamente aos casos acompanhados pelos estagiários no início dos anos 8o, os primeiros casos com que se deparam actualmente os futuros psicólogos são muito mais complexos, frequentemente crianças ou jovens com múltiplos problemas, que necessitam do envolvimento do contexto familiar, escolar, de justiça ou de saúde. Como é realçado por outros autores, os problemas das crianças, adolescentes e famílias no século XXI são mais graves e intensos, são multi-determinados e exigem avaliações e intervenções a diferentes níveis e contextos (Roberts \& Sobel, 1999).

Quanto às fontes de referência, as principais residem nos profissionais que mais contacto têm com a população mais jovem: professores e psicólogos escolares. Se em muitos casos o encaminhamento para os nossos Serviços se deve ao facto das crianças a presentarem problemas que não é adequado acompanhar em contexto escolar, em muitos outros, particularmente no que se refere ao insucesso escolar e às dificuldades na aprendizagem, esse encaminhamento ocorre pela impossibilidades dos Serviços de Psicologia das escolas fazerem o acompanhamento, por serem inexistentes ou por terem escassos recursos humanos.

Relativamente aos problemas identificados, verifica-se que, ao contrário das queixas iniciais, estes passam a ser na sua maioria de cariz internalizante (ansiedade, reacções ao stress, competências interpessoais inadequadas) ou resultam de situações exteriores à criança como é o caso de expectativas ou práticas parentais inadequadas. Tal como Yeh e Weisz (2001) verificaram, existe pouco acordo acerca de objectivos terapêuticos entre os pais e os filhos, sendo que os primeiros mais facilmente identificam problemas externalizantes e os segundos internalizantes.

A frequência elevada de casos com insucesso escolar inferior às capacidades demonstradas, deve-se a dois motivos principais: estratégias e hábitos de estudo inadequados e falta de motivação para a aprendizagem escolar devido a crenças pessoais (percepções de competência e de controlo) inadequadas. Muitos destes casos necessitam de intervenções complementares em contexto escolar para a recuperação na aquisição de conhecimentos.

A duração média das intervenções, 12 sessões, e a maioria se situar entre 1 e 20 sessões, sendo o número máximo de 29 , indica que a modalidade utilizada é a 
mais adequada a este tipo de serviço cujos atendimentos não devem ultrapassar o período de um ano lectivo e cuja eficácia parece ser adequada às necessidades dos utentes. Quando há abandonos do acompanhamento, estes ocorrem geralmente em fases precoces do processo de avaliação e intervenção devido à indisponibilidade das famílias para manter a regularidade e a pontualidade nos atendimentos.

Por último, as estratégias de intervenção mais utilizadas vão ao encontro dos conhecimentos adquiridos pelos estudantes nas disciplinas teóricas e abrangem os principais métodos de intervenção cognitivo-comportamental com crianças, adolescentes e pais. Deste modo, os estagiários são confrontados com experiências de aprendizagem adequadas para o seu nível inicial de formação clínica.

A supervisão clínica é um processo fundamental na formação dos psicoterapeutas que tenha em conta a qualidade da formação. Especificamente no contexto do Ensino Superior, o supervisor tem a dupla responsabilidade de ajudar o terapeuta iniciado a tornar-se mais competente e assegurar-se cuidadosamente do bem-estar do paciente.

Como já foi dito, parte do processo de se tornar terapeuta envolve o desenvolvimento de um sentido de identidade profissional. Segundo Perris (1994), as oportunidades de aprendizagem no contexto da supervisão podem ser conceptualizadas segundo três grandes fases: "aprendizagem inicial", "aprendizagem correctiva”, e "aprendizagem criativa".

Durante a primeira fase, quando um supervisando inicia o seu treino clínico basicamente está a tentar aprender a "fazer" terapia e, para começar, tem de definir o seu papel inicial na relação de supervisão. Alguns autores identificaram este estádio em termos de dependência e identificação (Stoltenberg, 1981), referindo-se à circunstância óbvia de que o supervisor, implícita ou explicitamente, representa um modelo para o formando que este irá mais tarde provavelmente imitar. Os supervisandos estão inicialmente muito ansiosos e preocupados com a sua aparente ausência de competências, pelo que imitam o seu supervisor e exigem indicações concretas.

À medida que a confiança do supervisando aumenta, o supervisor ajuda-o a entrar num estádio correctivo através de interpretações e técnicas. A aprendizagem correctiva torna o supervisando consciente dos erros que cometeu e ensina-o a evitar erros semelhantes no futuro, bem como lhe permite detectar lacunas nos seus conhecimentos que devem ser preenchidas. Uma das vantagens da supervisão em pequenos grupos é que os participantes podem, por seu turno, assumir ocasionalmente o papel de supervisor dando-lhes assim a oportunidade de desenvolver as suas competências críticas. 
Finalmente, surge um estádio criativo em que o estudante encontra o seu próprio estilo e identidade e consegue trabalhar apropriadamente com o seu paciente (Lecomte, Castonguay, Cyr, \& Sabourin, 1993). Nesta fase, o supervisando atinge uma compreensão mais profunda das relações interpessoais e a habilidade para retirar uma experiência terapêutica construtiva dessas relações com o paciente. Neste processo, o papel fundamental do supervisor parece ser o de ajudar o formando a construir um self profissional coerente e estável. Um supervisor que transmite respeito, seja genuíno e empático estabelecerá uma relação de confiança em que o desenvolvimento pessoal e profissional e o desenvolvimento clínico são facilitados. Comunicar um sentimento de aceitação contribui para aumentar a auto-estima e a manifestação de estilos pessoais nos supervisandos (Lecomte, Castonguay, Cyr, \& Sabourin, 1993).

Por último, importa salientar que o aspecto da imitação é crucial quando se trata da transmissão pelo exemplo de valores e atitudes. Segundo Perris (1994) "é só através do seu papel enquanto modelo que o supervisor consegue transmitir a atitude humanista de compreensão, respeito, humildade e tolerância para com os pacientes que seria impossivel aprender com a leitura de manuais" (p.96).

A psicoterapia é muito mais do que a aplicação de técnicas ou estratégias de intervenção, envolve uma relação interpessoal e o desenvolvimento da capacidade de "estar" com o outro num contexto de ajuda. Nesta área só a atitude e o exemplo do supervisor na forma como modela o relacionamento com os pacientes, como se relaciona com os seus supervisandos e a sensibilidade com que analisa e discute cada caso são fundamentais.

\section{Referências bibliográficas}

Beck, A. T. (1976). Cognitive therapy and emotional disorders. N.Y.: International Universities Press. Bernard, J.M., \& Goodyear, R.K. (1992). Fundamentals of clinical supervision. Needham Heights, MA: Allyn \& Bacon.

Enéas, M.L.E., Faleiros, J.C., \& Sá, A.C.A. (2000). Uso de psicoterapias breves em clínica-escola: caracterização dos processos com adultos. Psicologia: Teoria e Prática, 2, 9-30.

Lecomte, C., Castonguay, L.G., Cyr, M., \& Sabourin, S. (1993). Supervision and instruction in Doctoral Psycchotherapy Integration. In George Stricker \& Jerold R. Gold (Eds.), Comprehensive Handbook of Psychotherapy Integration (pp.483-498). N.Y.: Plenum Press.

Osofsky, J.D. (2005). Professional training in Infant Mental Health. Introdutory overview. Infants \& Young Children, 18, 266-268.

Peres, R.S., Santos, M.A., \& Coelho, H.M.B. (2004). Perfil da clientela de um programa de pronto-atendimento psicológico a estudantes universitários. Psicologia em Estudo, 9, 47-54.

Perris, C. (1994). Supervising Cognitive Psychotherapy and training supervisors. Journal of Cognitive Psychotherapy: An International Quarterly, 8, 83-103. 
Romaro, R.A., \& Capitão, (2003). Caracterização da clientela da clínica-escola de psicologia da Universidade de São Francisco. Psicologia: Teoria e Prática, 5, 111-121.

Roberts, M. C., \& Sobel, A. B. (1999). Training in clinical child psychology: Doing it right. Journal of Clinical Child Psychology, 28, 482-489.

Safran, J. D., \& Muran, J.C. (2001). A relational approach to training and supervision in cognitive psychotherapy. Journal of Cognitive Psychotherapy: An International Quarterly, 15, 3-15. Stoltenberg, C.D. (1981). Approaching supervision from a developmental perspective: The counselor complexity model. Journal of Counseling Psychology, 28, 59-65.

Yeh, M., Weisz, J. R. (2001). Why are we here at the clinic? Parent-child (dis)agreement on referral problems at outpatient treatment entry. Journal of Consulting and Clinical Psychology, 69, 1018-1025.

Yogev, S. (1982). An eclectic model of supervision: A developmental sequence for begining psychotherapy students. Professional Psychology, 13, 236-243.

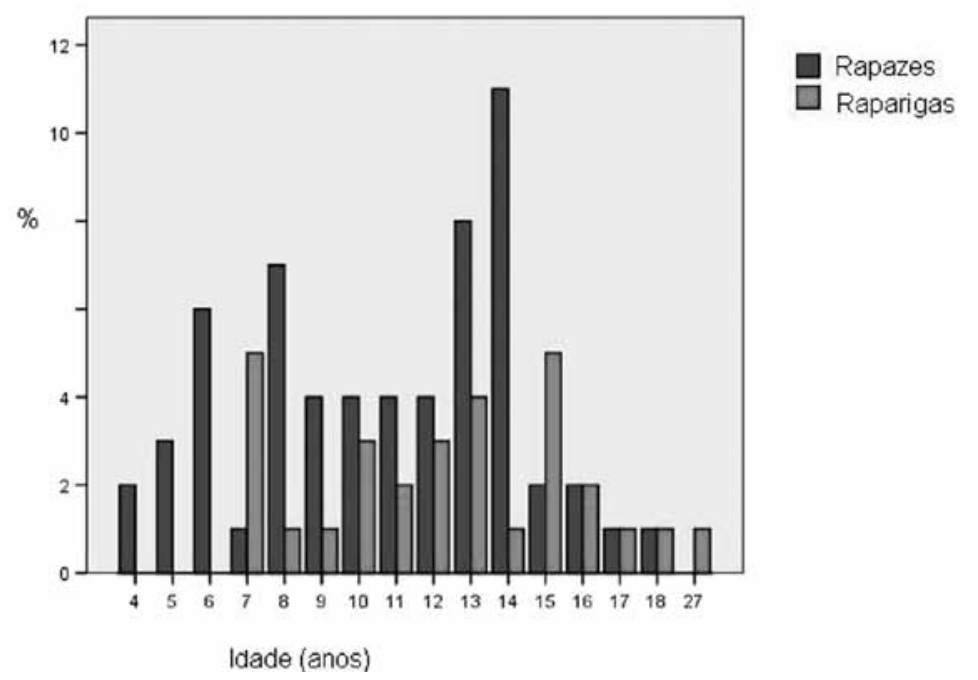

Figura 1. Distribuição dos participantes por idade e sexo. 
Quadro 1. Distribuição da amostra pelos anos e níveis de escolaridade.

\begin{tabular}{|c|c|c|c|c|c|}
\hline Ano de Escolaridade & $\mathbf{N}^{\circ}$ casos & $\%$ & Nível & $\mathbf{N}^{\circ}$ Casos & $\%$ \\
\hline Jardim de Infância & 4 & 5,0 & Pré-escola & 4 & 5,0 \\
\hline $1^{\circ}$ Ano & 8 & 10,0 & \multirow{4}{*}{$1^{\circ} \mathrm{Ciclo}$} & \multirow{4}{*}{28} & \multirow{4}{*}{35,1} \\
\hline $2^{\circ}$ Ano & 7 & 8,8 & & & \\
\hline $3^{\circ}$ Ano & 6 & 7,5 & & & \\
\hline $4^{\circ}$ Ano & 7 & 8,8 & & & \\
\hline $5^{\circ}$ Ano & 6 & 7,5 & \multirow{2}{*}{$2^{\circ}$ Ciclo } & \multirow{2}{*}{12} & \multirow{2}{*}{15,0} \\
\hline $6^{\circ}$ Ano & 6 & 7,5 & & & \\
\hline $7^{\circ}$ Ano & 10 & 12,5 & \multirow{3}{*}{$3^{\circ} \mathrm{Ciclo}$} & \multirow{3}{*}{27} & \multirow{3}{*}{33,8} \\
\hline $8^{\circ}$ Ano & 6 & 7,5 & & & \\
\hline $9^{\circ}$ Ano & 11 & 13,8 & & & \\
\hline $10^{\circ}$ Ano & 5 & 6,3 & \multirow{3}{*}{ Secundário } & \multirow{3}{*}{7} & \multirow{3}{*}{8,9} \\
\hline $11^{\circ}$ Ano & 0 & o & & & \\
\hline $12^{\circ}$ Ano & 2 & 2,6 & & & \\
\hline
\end{tabular}

Quadro 2. Número de ocorrências e percentagem por tipo de queixa apresentada.

\begin{tabular}{lccc}
\hline & Queixa & No Casos & $\%$ \\
\hline Agressividade & 7 & 7,5 \\
\hline Isolamento Social & 5 & 5,4 \\
\hline Ansiedade & 3 & 1,3 \\
\hline Insucesso escolar & 28 & 30,1 \\
\hline Dificuldades de Aprendizagem & 6 & 6,5 \\
\hline Défice de Atenção & 7 & 7,5 \\
\hline Problemas de Comportamento & 12 & 13,0 \\
\hline Medos & 2 & 2,2 \\
\hline Enurese & 2 & 2,2 \\
\hline Gaguez & 1 & 1,1 \\
\hline Morte de Familiar & 5 & 5,4 \\
\hline Divórcio dos Pais & 6 & 6,5 \\
\hline Défice Cognitivo & 6 & 6,5 \\
\hline Abuso Sexual & 1 & 1,1 \\
\hline
\end{tabular}


Quadro 3. Ocorrências e percentagem das Fontes de referência.

\begin{tabular}{lccc}
\hline \multicolumn{1}{c}{ Referência } & $\mathbf{N}^{\circ}$ Casos & $\%$ \\
\hline Estudante da Faculdade & 7 & 7,5 \\
\hline Antigo Estudante da Faculdade & 7 & 7,5 \\
\hline Docente da Faculdade & 10 & 10,8 \\
\hline Funcionário da Faculdade & 2 & 2,2 \\
\hline Antigo Cliente & 7 & 7,5 \\
\hline Professores & 13 & 14,0 \\
\hline Médicos & 3 & 3,2 \\
\hline Psicólogos Escolares & 10 & 10,8 \\
\hline Linha de Ajuda & 1 & 1,1 \\
\hline Sistema de Justiça & 1 & 1,1 \\
\hline
\end{tabular}

Quadro 4. Ocorrências e percentagem dos problemas identificados.

\begin{tabular}{lcc}
\hline \multicolumn{1}{c}{ Problemas Identificados } & $N^{\circ}$ de Casos & $\%$ \\
\hline Insucesso Escolar & 16 & 17,2 \\
\hline Crenças Parentais Inadequadas & 9 & 9,7 \\
\hline Enurese & 3 & 3,2 \\
\hline Défice Cognitivo & 4 & 4,3 \\
\hline Competências Interpessoais Inadequadas & 12 & 12,9 \\
\hline Défice de Atenção & 2 & 2,2 \\
\hline Ansiedade & 13 & 14 \\
\hline Dificuldades de Relacionamento entre pais e & 5 & 5,4 \\
filhos & & 3,2 \\
\hline Problemas de Comportamento & 3 & 2,2 \\
\hline Reacções ao Stress & 2 & 1,1 \\
\hline Depressão & 1 & \\
\hline
\end{tabular}

Quadro 5. Intervenções cognitivo-comportamentais realizadas

\begin{tabular}{lccc}
\hline \multicolumn{1}{c}{ Estratégias de Intervenção } & N $^{\circ}$ Casos & $\%$ \\
\hline Intervenções psico-educativas com pais & 14 & 17,5 \\
\hline Treino de auto-controlo & 18 & 22,5 \\
\hline Treino de resolução de problemas & 12 & 15,0 \\
\hline Reestruturação cognitiva & 12 & 15,0 \\
\hline Treino de competências sociais & 5 & 6,3 \\
\hline
\end{tabular}




\section{La formation initiale des thérapeutes d'enfants: le Service Clinique à la Faculté de Psychologie de l'Université de Lisbonne}

Les objectifs de cette étude sont: (a) de décrire l'intervention psychologique du Service d'Accueil Clinique du Département Cognitif, Comportementaux et Intégratif de la FPCE-UL en ce qui concerne les modalités d'intervention e de supervision clinique; et (b) de caractériser les enfants, adolescents et parents qui y demandent de l'aide, relativement à leur genre, âge, niveau socioculturel, problèmes et références. On a utilisé une méthodologie documentaire rétrospective par l'analyse de processus cliniques. Pendant les derniers huit ans, le Service a accueilli 93 enfants et adolescents (61 garçons et 32 filles), âgés de 4 à 18 ans $(M=11,3)$, ayant de divers problèmes émotionnels et comportementaux dont les interventions ont une durée moyenne de 12 sessions. Ces résultats sont analysés en fonction de leurs implications dans l'adéquation de ce Service Clinique à la formation initiale des psychologues.

MOTS-CLÉS: thérapie des enfants; supervision clinique; formation des psychologues; accueil psychologique.

Training beginning child therapists: the case of the school-clinic at the University of Lisbon

The purposes of this paper are to: (a) describe the clinical service delivery by psychology post-graduate students (intervention modalities and clinical supervision); and (b) characterize children, adolescents, and parents that ask for help (according to gender, age group, educational level, presenting problems and referrals). We used a documented retrospective methodology through the analysis of clinical files. The data shows that in the last 8 years the clinic attended to 93 children and adolescents ( 61 boys and 32 girls), aging from 4 to 18 years old $(M=11,3)$, presenting a wide range of behavioural and emotional problems, and the intervention processes are concluded between 1 and 29 sessions $(M=12)$. We discuss how the analysis of this characterization has supported changes in the services and the advantages and limitations of this kind of clinic for the training of beginning therapist in a cognitive and behavioural modality.

KEY-WORDS: child therapy; clinical supervision; school-clinic; therapist training. 